\title{
Ultrasonic-assisted Extraction, Antioxidant Activity and Structural Characterization of Polysaccharides from Oenothera Biennis L. Leaves
}

\author{
Zhou Yong Dong ${ }^{1 a *}$, Xin Song Yin ${ }^{1}$, Shu Lin Liu ${ }^{1}$, Tie Hua Zhang ${ }^{1}$, Hui Ren ${ }^{1}$, Hai Yun Tan ${ }^{2 b *}$ \\ ${ }^{1}$ College of food science and engineering, Jilin University, 130062, Changchun, Jilin, China \\ ${ }^{2}$ Institute of Agricultural Resources and Environment, Tibet Academy of Agricultural and Animal Husbandry Science, 850000, Lhasa, \\ Tibet, China
}

\begin{abstract}
This paper studies the optimization of ultrasonic-assisted extraction of polysaccharides from Oenothera biennis L. leaves using Box-Behnken design, and their in vitro antioxidant activity and structure. It is demonstrated that the optimum extraction conditions are: the ultrasonic power at $400 \mathrm{~W}$, solvent-tosample ratio of $23: 1(\mathrm{~mL} / \mathrm{g})$, ultrasonication temperature at $53{ }^{\circ} \mathrm{C}$, and time for $36 \mathrm{~min}$, under which the yield of polysaccharides from Oenothera biennis L. leaves, namely $3.54 \%$, remains close to the predicted value in the model. The assays of the scavenging effect on DPPH and hydroxyl free radicals, and of the reducing power indicate that polysaccharides from Oenothera biennis L. leaves possess strong antioxidant activity and certain relationship exists between their dose and effect in the concentration range of the experiment; Fourier IR spectroscopy reveals that characteristic absorption peak of polysaccharides can be seen from the sample; the DE-52 cellulose column chromatography, HPLC profiles, and GC-MS chromatogram identify the obtained OCP-2 as heteropolysaccharides, whose major components, including arabinose, mannose, galactose, and talose, have an average molecular weight of $5435 \mathrm{Da}$
\end{abstract}

\section{Introduction}

Oenothera biennis L., also known as Radix helicteris or evening primrose, is a herbaceous biennial of the Onagraceae family native to South and North America. Around twenty types of Oenothera biennis L. have already been found in China ${ }^{[1]}$, mainly distributed in Guizhou Province, North and Northeast China. They contain the active ingredients of flavonoid, phenols, polysaccharides, and lipids that have antiviral, antiinflammatory, and antioxidant activity ${ }^{[2]}$. The current exploitation of Oenothera biennis L. centers on its seed oil, whereas virtually all of its stems and leaves are discarded, leaving resources wasted and environment polluted. Plant polysaccharides physiologically possess immune enhancement, anti-tumor, anti-aging, antiradiation and hypoglycemic activity ${ }^{[3]}$. Among the few studies existing by far on polysaccharides from Oenothera biennis L. leaves is the preliminary one conducted by Zeng, et al ${ }^{[4]}$ concentrating on their effects on tumor suppression, while the research on their ultrasonic-assisted extraction, antioxidant activity, structure characterization, and separation and purification is very scarce.

To provide useful references for the comprehensive exploitation of Oenothera biennis L., this experiment identifies the optimal conditions required for such polysaccharide extraction that is optimized by response surface methodology (RSM); the scavenging effect on DPPH and hydroxyl free radicals, and the reducing power are assayed to study the in vitro antioxidant activity; Fourier IR spectroscopy is employed to identify the basic structure characterization; the DE-52 cellulose column chromatography works to purify obtained polysaccharides, and HPLC profiles and GC-MS chromatogram are used to analyze the average molecular weight and monosaccharide composition.

\section{Materials and Methods}

\subsection{Materials and reagents}

Oenothera biennis L. Leaves, Jilin Shengji (excellence with a solid foundation) Industrial Co., LTD., dry to constant weight at $60{ }^{\circ} \mathrm{C}$, pulverize and sieve with 40 mesh screen, degrease with Soxhlet extractor, and then keep in the refrigerator at $-20{ }^{\circ} \mathrm{C}$; 1,1-diphenyl-2picrylhydrazyl (DPPH) Sigma; ascorbic acid $\left(\mathrm{V}_{\mathrm{C}}\right)$, Tianjin Guangfu Fine Chemical Research Institute; DE52 cellulose Whatman; ferrous sulfate heptahydrate, ethylenediaminetetraacetic acid (EDTA), ammonium molybdate tetrahydrate, monosodium phosphate, and disodium hydrogen phosphate, which are all analytical reagents.

\footnotetext{
* Corresponding author: adongzhouyong3421@163.com

bloveyunzi@163.com
} 


\subsection{Methods}

\subsubsection{Extraction of polysaccharides from Oenothera biennis L. leaves}

Accurately weigh a certain amount of Oenothera biennis L. leaves powder, add a certain proportion of distilled water, conduct ultrasonication(ultrasonic apparatus, KQ$400 \mathrm{KDV}$, Kunshan, China) for a certain period of time, and then centrifuge for $10 \mathrm{~min}$ at $4000 \mathrm{rpm}$. Take supernatant and add ethanol until its volume fraction reaches $80 \%$, and leave it overnight in a refrigerator at $4{ }^{\circ} \mathrm{C}$ before further centrifugation. Wash the precipitate with anhydrous ethanol, acetone, ether respectively until it appears colorless, and then lay it in a fume hood so as to evaporate it to dryness. The resulting crude extract is the exact crude polysaccharides from Oenothera biennis L. leaves (OCP).

\subsubsection{Extraction optimization of OCP by response surface methodology (RSM)}

According to the experiment results, the Box-Behnken design is adopted in which ultrasonic power, solvent-tosample ratio, ultrasonication time and temperature are considered as variables to be investigated, while the yield of polysaccharides as response value. Their coded and uncoded levels are as shown in Table 1.

Table 1 Coded and uncoded levels of independent variables used for Box-Behnken design(BBD)

\begin{tabular}{|c|c|c|c|c|}
\hline \multirow[b]{2}{*}{ levels } & \multicolumn{4}{|c|}{ variables } \\
\hline & $\begin{array}{c}X_{1} \\
\text { ultraso } \\
\text { nic } \\
\text { power } \\
\text { /w } \\
\end{array}$ & $\begin{array}{c}X_{2} \\
\text { solvent-to- } \\
\text { sample } \\
\text { ratio } \\
(\mathrm{mL} / \mathrm{g}) \\
\end{array}$ & $\begin{array}{c}X_{3} \\
\text { ultrasonica } \\
\text { tion } \\
\text { time } / \mathrm{min}\end{array}$ & $\begin{array}{c}X_{4} \\
\text { ultrasonicat } \\
\text { ion } \\
\text { temperatur } \\
\mathrm{e} /{ }^{\circ} \mathrm{C} \\
\end{array}$ \\
\hline-1 & 320 & $10: 1$ & 30 & 45 \\
\hline 0 & 360 & $15: 1$ & 40 & 55 \\
\hline 1 & 400 & $20: 1$ & 50 & 65 \\
\hline
\end{tabular}

\subsubsection{Assay of polysaccharides yield}

The phenol-sulfuric acid method ${ }^{[5]}$ is employed to determine the polysaccharide content in crude polysaccharides, while glucose is used as the standard.

$$
\text { the polysaccharide yield } \quad / \%=\frac{m}{M} \times 100
$$

In the formula, $m$ and $M$ are respectively the mass of polysaccharides in crude polysaccharides ( $\mathrm{g}$ ) and the mass of Oenothera biennis L. leaves powder (g).

\subsubsection{Study on the antioxidant activity of OCP}

Take and deproteinize OCP by the Sevage method ${ }^{[6]}$, add anhydrous ethanol until the volume fraction reaches $80 \%$, and let it stand overnight at the temperature of $4{ }^{\circ} \mathrm{C}$. Centrifuge, dry the precipitate, and refrigerate for later use.

\subsubsection{Assay of the scavenging effect on $D P P H$ free radicals}

Employ the method used by Poppe, et al ${ }^{[7]}$ but make a slight modification. Take $1 \mathrm{~mL}$ of sample solution of different concentrations respectively, add $2 \mathrm{~mL}$ of DPPH solution ( $0.1 \mathrm{mmol}$ dissolved in $95 \%$ ethanol), shake well immediately, and react for $30 \mathrm{~min}$ at room temperature in the dark. Measure the absorbance at a wavelength of $517 \mathrm{~nm}$ after the reaction is complete. Take $1 \mathrm{~mL}$ of distilled water plus $2 \mathrm{~mL}$ of $95 \%$ ethanol as a reference, and take ascorbic acid $\left(\mathrm{V}_{\mathrm{C}}\right)$ as a positive control. The scavenging rate of DPPH free radicals is calculated by the following formula:

the scavenging rate $\quad / \%=\left(1-\frac{A_{1}-A_{2}}{A_{0}}\right) \times 100$

where $A_{1}$ is the absorbance of $1 \mathrm{~mL}$ of sample plus $2 \mathrm{~mL}$ DPPH solution; $A_{2}$ is the absorbance of $1 \mathrm{~mL}$ sample solution plus $2 \mathrm{~mL}$ of $95 \%$ ethanol; $A_{0}$ is the absorbance of $2 \mathrm{~mL}$ DPPH solution plus $1 \mathrm{~mL}$ of distilled water.

\subsubsection{Assay of the scavenging effect on hydroxyl free radicals $(\cdot \mathrm{OH})$}

Take $1 \mathrm{~mL}$ of sample solution of different concentrations respectively, and add $1 \mathrm{~mL}$ of $10 \mathrm{mmol} / \mathrm{L}$ salicylic acid solution of alcohol and $1 \mathrm{~mL}$ of $10 \mathrm{mmol} / \mathrm{L}$ ferric sulfite solution. One minute later, add $1 \mathrm{~mL}$ of $10 \mathrm{mmol} / \mathrm{L}$ hydrogen peroxide solution, and react for $30 \mathrm{~min}$ in a $37{ }^{\circ} \mathrm{C}$ water bath in the dark. Measure the absorbance at a wavelength of $510 \mathrm{~nm}$, and take ascorbic acid $\left(\mathrm{V}_{\mathrm{C}}\right)$ as a positive control. The scavenging rate of hydroxyl free radicals is calculated by the following formula:

the scavenging rate $\quad / \%=\left(1-\frac{A_{1}-A_{2}}{A_{3}}\right) \times 100$

where $A_{1}$ is the absorbance of $1 \mathrm{~mL}$ of sample plus the mixed solution; $A_{2}$ is the absorbance of replacing hydrogen peroxide solution with $1 \mathrm{~mL}$ of distilled water to react; $A_{3}$ is the absorbance of replacing sample solution with $1 \mathrm{~mL}$ of distilled water to react.

\subsubsection{Assay of the reducing power}

Employ the method used by Lai, et $\mathrm{al}^{[8]}$ but make a slight modification. Take $1 \mathrm{~mL}$ of sample solution of different concentrations, add $2.5 \mathrm{~mL}$ of $0.2 \mathrm{M}$ phosphate solution $(\mathrm{pH}=6.6)$ and $2.5 \mathrm{~mL}$ of $1 \%$ potassium ferricyanide solution, and place in a $50{ }^{\circ} \mathrm{C}$ water bath for $20 \mathrm{~min}$. Then add $2.5 \mathrm{~mL}$ of $10 \%$ trichloroacetic acid (TCA) solution and centrifuge at $3500 \mathrm{r} / \mathrm{min}$ for $10 \mathrm{~min}$. Take $2.5 \mathrm{~mL}$ of supernatant, quickly add $0.5 \mathrm{~mL}$ distilled water and $0.5 \mathrm{~mL}$ of $0.1 \%$ ferric chloride solution, and let it stand for $15 \mathrm{~min}$ at room temperature before measuring the absorbance at a wavelength of $700 \mathrm{~nm}$. Take ascorbic acid $\left(\mathrm{V}_{\mathrm{C}}\right)$ as a positive control.

\subsubsection{IR spectroscopy analysis of OCP}

Use $\mathrm{KBr}$ pellets. Weigh $200.0 \mathrm{mg}$ of $\mathrm{KBr}$ and $2.0 \mathrm{mg}$ of OCP that have been dried to constant weight. Mix, grind, 
and make a pellet, and then scan it under an infrared spectrometer at a wavelength of $4000-400 \mathrm{~cm}^{-1}$.

\subsubsection{Separation and purification of OCP}

Convert the above-mentioned OCP to a solution with a mass concentration of $10 \mathrm{mg} / \mathrm{mL}$, allow the DE-52 cellulose column to equilibrate with distilled water, load $3 \mathrm{~mL}$ of sample, elute the column with distilled water first and then with $0.1,0.2$ and $0.3 \mathrm{~mol} / \mathrm{L} \mathrm{NaCl}$ solution respectively at $1.0 \mathrm{~mL} / \mathrm{min}$, and collect a tube every three minutes. Detect polysaccharides using the phenolsulfuric acid method, draw a graph, and collect eluate that reveals a single peak.

\subsubsection{Assay of the molecular weight of polysaccharides}

The purity and average molecular weight of polysaccharides are determined by high performance liquid chromatography (HPLC). The column is TSKGEL G3000 PWXL $(300 \mathrm{~mm} \times 7.8 \mathrm{~mm})$, the mobile phase is ultrapure water with a column temperature of $40{ }^{\circ} \mathrm{C}$ at a flow rate of $0.5 \mathrm{~mL} / \mathrm{min}$, the sample is 2 $\mathrm{mg} / \mathrm{mL}$, and the injection volume is $20 \mu \mathrm{L}$. Draw a standard curve with the logarithm of the molecular weight of standard polysaccharide sample $\left(\operatorname{lgM}_{W}\right)$ as the ordinate and the retention time of sample peak as the abscissa, and calculate the average molecular weight of polysaccharide components.

\subsubsection{Assay of polysaccharide components}

Identify the components in polysaccharide sample using GC-MS, take $10 \mathrm{mg}$ of polysaccharides and dissolve in $2 \mathrm{~mL}$ of $2 \mathrm{~mol} / \mathrm{L}$ trifluoroacetic solution, and seal the tube by nitrogen. Hydrolyze at $110{ }^{\circ} \mathrm{C}$ for $5 \mathrm{~h}$, remove trifluoroacetic acid under reduced pressure, add $30 \mu \mathrm{L}$ of silanization reagent and $100 \mu \mathrm{L}$ of pyridine to the remaining product, seal the tube, react at $100{ }^{\circ} \mathrm{C}$ for 60 $\mathrm{min}$, and then cool to room temperature. Concentrate it under reduced pressure to dryness, and add $0.5 \mathrm{~mL}$ of chloroform solution to dissolve for later experiment. GC conditions: quartz capillary separation columns (HP-5,

$30 \mathrm{~m} \times 250 \mu \mathrm{m} \times 0.25 \mu \mathrm{m})$, the carrier gas of helium, a flow rate of $1.0 \mathrm{~mL} / \mathrm{min}$, an inlet temperature of $280{ }^{\circ} \mathrm{C}$ and interface of $280{ }^{\circ} \mathrm{C}$, and temperature programming: maintain the initial temperature of $80{ }^{\circ} \mathrm{C}$ for $5 \mathrm{~min}$ before increasing it to $290{ }^{\circ} \mathrm{C}$ by $10{ }^{\circ} \mathrm{C} / \mathrm{min}$. MS conditions: electron impact iron source, the electron energy of $70 \mathrm{ev}$, an iron source temperature of $230{ }^{\circ} \mathrm{C}$, and a scan range of 20-700 amu.

\subsubsection{Statistical Analysis}

Use the software Design-Expert8.0.6 to conduct a quadratic regression and variance analysis of the optimization of polysaccharide extraction, and apply the software Origin7.0 to the statistical analysis of all the other experimental data. Repeat all the experiments three times.

\section{Results and Discussion}

\subsection{Optimization of polysaccharide extraction by response surface methodology}

\subsubsection{Design and results for response surface analysis}

Table 2 Experiment design and results for response surface analysis.

\begin{tabular}{|c|c|c|c|c|c|}
\hline No. & $X_{1}$ & $X_{2}$ & $X_{3}$ & $X_{4}$ & $\begin{array}{c}Y \text { polysaccharides } \\
\text { yield } / \% \\
\end{array}$ \\
\hline 1 & 0 & 0 & 0 & 0 & 3.49 \\
\hline 2 & -1 & 0 & -1 & 0 & 2.89 \\
\hline 3 & 0 & -1 & -1 & 0 & 2.49 \\
\hline 4 & 0 & -1 & 0 & -1 & 2.38 \\
\hline 5 & 1 & -1 & 0 & 0 & 2.84 \\
\hline 6 & -1 & 1 & 0 & 0 & 3.32 \\
\hline 7 & -1 & 0 & 0 & -1 & 3.01 \\
\hline 8 & 0 & 1 & -1 & 0 & 3.31 \\
\hline 9 & 0 & 0 & 0 & 0 & 3.37 \\
\hline 10 & 1 & 0 & 0 & -1 & 3.21 \\
\hline 11 & 0 & -1 & 1 & 0 & 2.67 \\
\hline 12 & 1 & 0 & 1 & 0 & 3.16 \\
\hline 13 & 0 & 0 & 0 & 0 & 3.36 \\
\hline 14 & -1 & 0 & 1 & 0 & 3.11 \\
\hline 15 & 0 & -1 & 0 & 1 & 2.44 \\
\hline 16 & 0 & 1 & 1 & 0 & 3.22 \\
\hline 17 & 0 & 0 & 0 & 0 & 3.46 \\
\hline 18 & 0 & 1 & 0 & 1 & 3.33 \\
\hline 19 & 1 & 1 & 0 & 0 & 3.45 \\
\hline 20 & 0 & 0 & -1 & 1 & 2.93 \\
\hline 21 & -1 & -1 & 0 & 0 & 2.79 \\
\hline 22 & 0 & 0 & -1 & -1 & 3.27 \\
\hline 23 & 1 & 0 & 0 & 1 & 3.43 \\
\hline 24 & 0 & 0 & 1 & 1 & 3.20 \\
\hline 25 & 0 & 1 & 0 & -1 & 3.41 \\
\hline 26 & -1 & 0 & 0 & 1 & 3.20 \\
\hline 27 & 0 & 0 & 1 & -1 & 3.15 \\
\hline 28 & 1 & 0 & -1 & 0 & 3.41 \\
\hline 29 & 0 & 0 & 0 & 0 & 3.47 \\
\hline
\end{tabular}

Experiment design and results for response surface analysis is as shown in Table 2, and analysis of variance in Table 3. Use the software Design-Expert8.0 to fit the quadratic regression model based on the data in Table 2, and a regression equation of polysaccharides yield can be obtained as follows:

$Y=3.43+0.098 X_{1}+0.37 X_{2}+0.0175 X_{3}+0.008333-$ $0.03 X_{4}+0.02 X_{1} X_{2}-0.12 X_{1} X_{3}+0.0075-0.03 X_{1} X_{4}-0.067 X_{2} X_{3}-$ $0.035 X_{2} X_{4}+0.098 X_{3} X_{4}-0.055 X_{1}^{2}-0.33 X_{2}^{2}-0.18 X_{3}^{2}-0.16 X_{4}^{2}$

Table 3 displays that this regression model $(P<$ 0.0001 ) is highly significant, whereas the lack of fit is 
non-significant. The model's coefficient of determination $R^{2}$ stands at 0.9241 , meaning that the experimental design is reliable to accurately predict the yield of OCP. The linear term of ultrasonic power is significant $(P<0.05)$, the linear term of solvent-to-sample ratio is extremely significant $(P<0.01)$, and the quadratic terms of solvent-to-sample ratio, ultrasonication time, and temperature are all extremely significant $(P<0.01)$. It is indicated that the relationship between various factors and the yield of polysaccharides is not linear ${ }^{[9]}$. The interaction between the four factors is non-significant, and the response surface and contour plot of the interaction are as shown in Figure 1. The influence of the four factors on the yield of polysaccharides is in the following order: solvent-to-sample ratio > ultrasound power $>$ ultrasonication time $>$ ultrasonication temperature.

Table 3 Analysis of variance table

\begin{tabular}{|c|c|c|c|c|c|}
\hline $\begin{array}{c}\text { sources } \\
\text { of } \\
\text { varianc } \\
\mathrm{e} \\
\end{array}$ & $\begin{array}{c}\text { degree } \\
\text { of } \\
\text { freedo } \\
\mathrm{m} \\
\end{array}$ & $\begin{array}{l}\text { sum of } \\
\text { squares }\end{array}$ & $\begin{array}{c}\text { mean } \\
\text { squares }\end{array}$ & $\begin{array}{c}F- \\
\text { value }\end{array}$ & $\begin{array}{c}P- \\
\text { value }\end{array}$ \\
\hline$X_{1}$ & 1 & 0.12 & 0.12 & 7.29 & 0.0173 \\
\hline$X_{2}$ & 1 & 1.64 & 1.64 & $\begin{array}{c}102.6 \\
8\end{array}$ & $\begin{array}{c}<0.000 \\
1\end{array}$ \\
\hline$X_{3}$ & 1 & 0.003675 & 0.003675 & 0.23 & 0.6384 \\
\hline$X_{4}$ & 1 & $\begin{array}{c}0.000833 \\
3\end{array}$ & $\begin{array}{c}0.000833 \\
3\end{array}$ & 0.052 & 0.8224 \\
\hline$X_{1} X_{2}$ & 1 & 0.0016 & 0.0016 & 0.1 & 0.756 \\
\hline$X_{1} X_{3}$ & 1 & 0.055 & 0.055 & 3.47 & 0.0837 \\
\hline$X_{1} X_{4}$ & 1 & 0.000225 & 0.000225 & 0.014 & 0.9071 \\
\hline$X_{2} X_{3}$ & 1 & 0.018 & 0.018 & 1.14 & 0.3028 \\
\hline$X_{2} X_{4}$ & 1 & 0.0049 & 0.0049 & 0.31 & 0.5879 \\
\hline$X_{3} X_{4}$ & 1 & 0.038 & 0.038 & 2.39 & 0.1446 \\
\hline$X_{1}^{2}$ & 1 & 0.02 & 0.02 & 1.23 & 0.2857 \\
\hline$X_{2}^{2}$ & 1 & 0.69 & 0.69 & 43.35 & $\begin{array}{c}<0.000 \\
\quad 1\end{array}$ \\
\hline$X_{3}^{2}$ & 1 & 0.21 & 0.21 & 13.38 & 0.0026 \\
\hline$X_{4}^{2}$ & 1 & 0.17 & 0.17 & 10.75 & 0.0055 \\
\hline model & 14 & 2.72 & 0.19 & 12.18 & $\begin{array}{c}<0.000 \\
1\end{array}$ \\
\hline residual & 14 & 0.22 & 0.016 & & \\
\hline $\begin{array}{c}\text { lack of } \\
\text { fit }\end{array}$ & 10 & 0.21 & 0.021 & 5.71 & 0.0539 \\
\hline $\begin{array}{l}\text { pure } \\
\text { error }\end{array}$ & 4 & 0.015 & 0.00365 & & \\
\hline sum & 28 & 2.94 & & & \\
\hline
\end{tabular}

As shown in Figure 1 (a-f), the three-dimensional surface plots formed by response factors and their contour plots on two dimensional plane make the influence imposed by these factors and their interaction visible. Comprehensive analysis of variance demonstrates that the interaction between any two factors is non-significant. Keep two of these factors at the level of zero alternately, and the influence imposed by the interaction of the other two factors on polysaccharides yield can be obtained. Figure 1 (a) displays that when the ultrasonic power remains constant, the yield of polysaccharides increases first and then decreases as ultrasonication time keeps increasing. The underlying reason is probably that a certain period of time is required for ultrasound to destroy the cell walls and an increasing number of destroyed cells arising from the increase of time allow more polysaccharides to dissolve in the solvent. Nevertheless, some polysaccharides will degrade due to the thermal effect produced as ultrasonication time continues to increase, causing a decrease in the yield of polysaccharides. When the ultrasonication time is invariable, the yield of polysaccharides increases slowly with the increase of ultrasonic power, which is possibly because the rupture of cell walls is aggravated by the increase in ultrasonic power and the enhanced cavitation effect, allowing more intracellular substances to dissolve. The interaction between ultrasonic power and ultrasonication temperature appears weak, which can only engender a smooth change in the yield of polysaccharides when ultrasonication time and solvent-to-sample ratio remain invariable. Figure 1 (b) shows that when the ultrasonic power remains constant, the increase of solvent-tosample ratio will cause the yield of polysaccharides to increase first before leveling off. The same holds true for the change of polysaccharides yield caused by solventto-sample ratio when ultrasonication time or temperature remains constant.
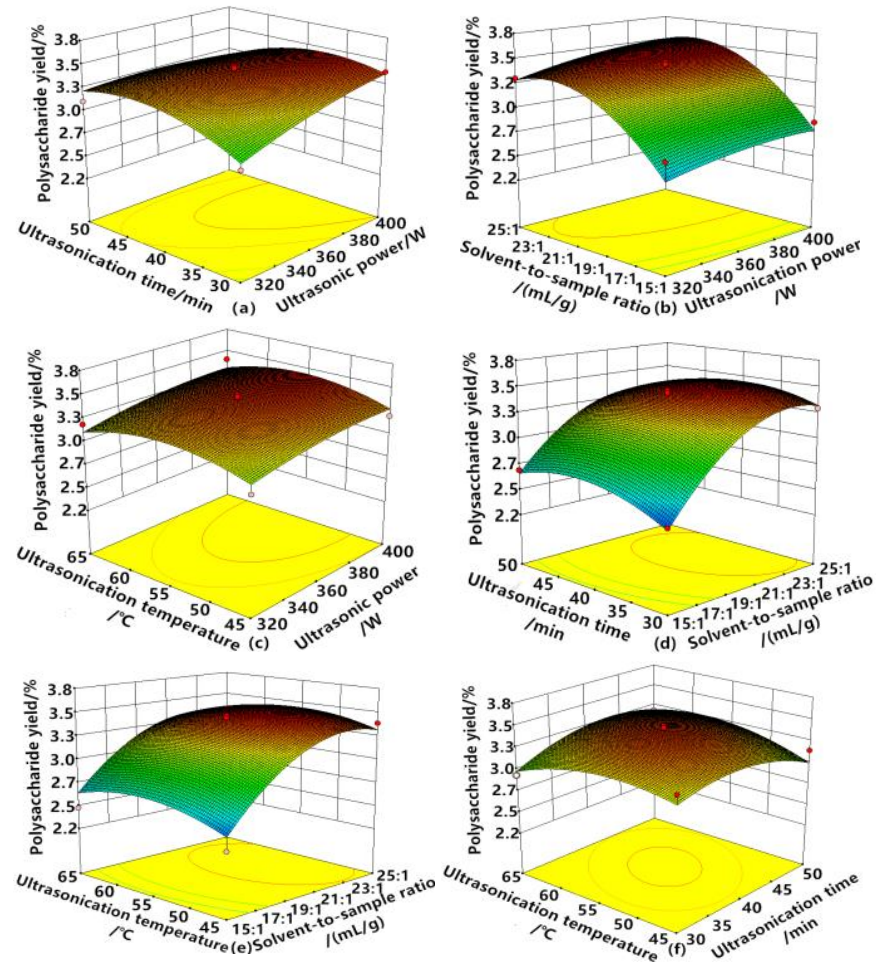

Fig.1. Response surface graphs showing the experimental factors and their combined effects on the yield of OCP

\subsubsection{Determination and verification of the optimum conditions}

Based on the analysis by the software DesignExpert8.0.6, the optimum extraction parameters are predicted as follows: the ultrasonic power at $400 \mathrm{~W}$, solvent-to-sample ratio of 23.25:1 (mL/g), ultrasonication temperature at $53.46{ }^{\circ} \mathrm{C}$, and time for $35.60 \mathrm{~min}$, and polysaccharides yield of $3.62 \%$. Given the practical operating conditions, the above parameters are modified as follows: the ultrasonic power at $400 \mathrm{~W}$, solvent-to-sample ratio $23: 1(\mathrm{~mL} / \mathrm{g})$, ultrasonication 
temperature at $53{ }^{\circ} \mathrm{C}$, and time for $36 \mathrm{~min}$, under which the yield of OCP is $3.54 \%$. In comparison with the modified predicted value, the relative error is merely $2.21 \%$.

\subsection{Antioxidant activity of OCP}

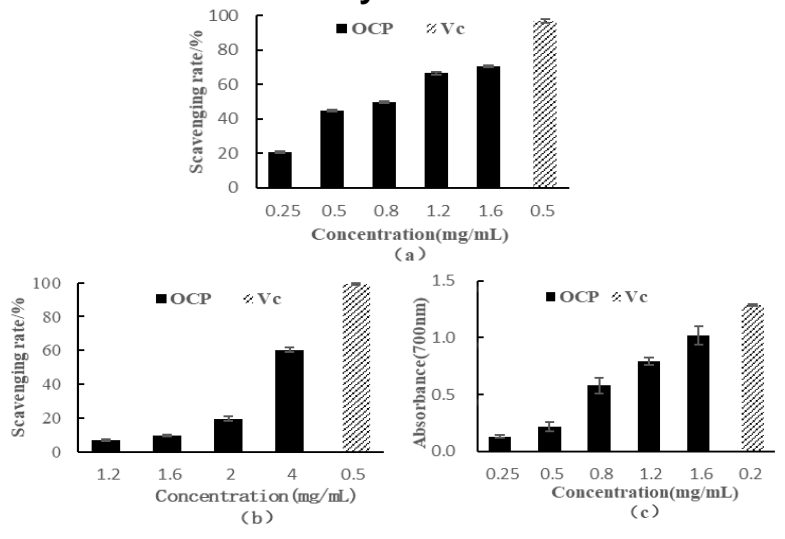

Figure 2. The antioxidant activity of OCP. (a) scavenging effect on DPPH free radicals, (b) scavenging effect on hydroxyl free radicals, (c) the reducing power

The scavenging effect on DPPH free radicals is beyond possibility without their ability to provide hydrogen atoms ${ }^{[10]}$. A small quantity of compounds react quickly with DPPH radicals, reducing the same number of DPPH molecules as that of their own hydroxyl radicals, while most compounds react slowly due to more complicated mechanisms $^{[11]}$. As shown in Figure 2(a), the scavenging effect on DPPH free radicals of OCP gets enhanced as the concentration increases, leveling off when the mass concentration exceeds $1.2 \mathrm{mg} / \mathrm{mL}$ and reaching $70.52 \%$ at the concentration of $1.6 \mathrm{mg} / \mathrm{mL}$. It is indicated that polysaccharides from Oenothera biennis L. leaves possess strong scavenging activity of DPPH free radicals and certain relationship exists between the dose and effect in the concentration range of the experiment.

Hydroxyl free radicals are so active that they are liable to react with and deactivate active substances in the body, or even worse, cause cancer. In Figure 2(b), OCP's scavenging effect on hydroxyl free radicals appears enhanced with the increase of concentration, reaching $60.36 \%$ at the mass concentration of $4 \mathrm{mg} / \mathrm{mL}$, which signifies a strong scavenging effect on hydroxyl free radicals. Polysaccharides from Oenothera biennis L. leaves owe their scavenging ability of hydroxyl free radicals to either the hydroxyl group possibly existing in their structure or the influence imposed by the density of electrons around heterocyclic carbon ${ }^{[12]}$.

Potassium ferricyanide $\left[\mathrm{K}_{3} \mathrm{Fe}(\mathrm{CN})_{6}\right]$ has its $\mathrm{Fe}^{3+}$ reduced by antioxidant to $\mathrm{Fe}^{2+}$, which can be detected by Prussian blue reaction at the wavelength of $700 \mathrm{~nm}$. A greater value of absorbance contributes to a stronger reducing power and antioxidant activity of the substance ${ }^{[13-14]}$. Figure 2(c) demonstrates that the reducing power of OCP becomes enhanced with the increase of mass concentration. The absorbance stands at 1.02 at the maximum mass concentration of $1.6 \mathrm{mg} / \mathrm{mL}$, indicating that polysaccharides from Oenothera biennis L. leaves possess strong reducing power and certain relationship exists between the dose and effect in the concentration range of the experiment.

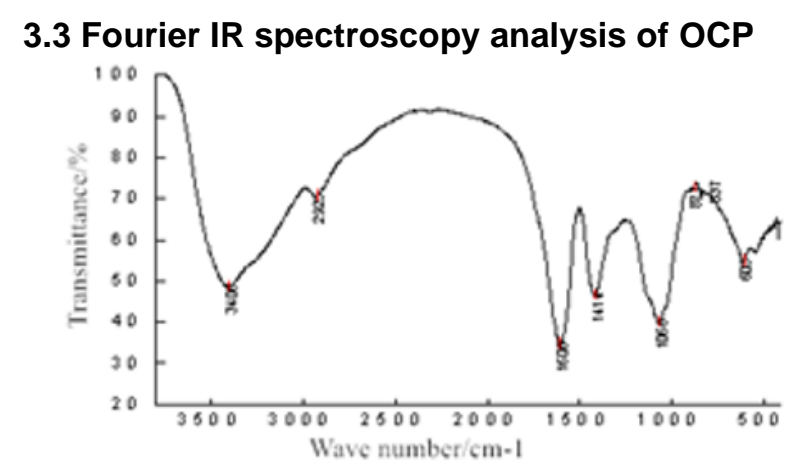

Fig. 3. IR spectroscopy of polysaccharides

The IR spectroscopy of OCP, which possesses the characteristic absorption peaks of polysaccharides, is as shown in Figure 3. The larger peak at $3406 \mathrm{~cm}^{-1}$ is assigned to the stretching vibration of intermolecular or intramolecular H-bonded O-H; at $2925 \mathrm{~cm}^{-1}$ exists a C-H vibration absorption peak; at $1606 \mathrm{~cm}^{-1}$ is the vibration absorption peak of $\mathrm{C}=\mathrm{O}$ in uronic acid, signifying the possible existence of carboxyl or carboxylate; at 1414 $\mathrm{cm}^{-1}$ is bending vibration absorption peak of $\mathrm{C}-\mathrm{H} ; 1066$ $\mathrm{cm}^{-1}$ displays the asymmetric stretching vibration of the glycosidic bond $\mathrm{C}-\mathrm{O}-\mathrm{C}$, indicating the presence of pyranoid ring conformation in polysaccharides; $837 \mathrm{~cm}^{-1}$ shows the characteristic absorption peak of $\alpha$-glycosidic bonds, meaning that the monosaccharide is $\alpha-D-$ glucopyranose ${ }^{[15-16]}$.

\subsection{Separation and purification of OCP}

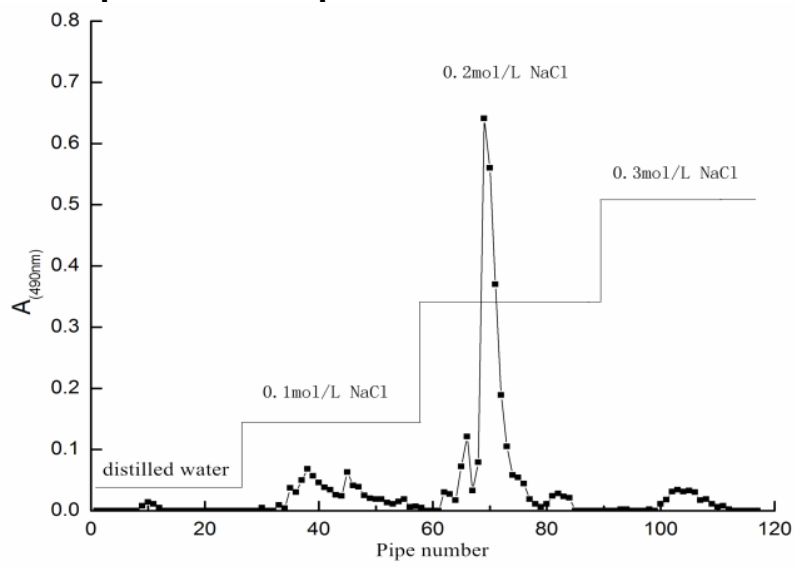

Fig.4. Elution curve of OCP on the DE- 52 cellulose column

Figure 4 demonstrates that during separating OCP through the DE-52 cellulose the peaks appear smaller when distilled water, and 0.1 and $0.3 \mathrm{~mol} / \mathrm{L} \mathrm{NaCl}$ are used for elution, while the largest one appears when 0.2 $\mathrm{mol} / \mathrm{L} \mathrm{NaCl}$ is used, a sign of the maximum quantity of OCP. Collect, concentrate, dialyze, and freeze-dry the subsequent fraction from the elution of $0.2 \mathrm{~mol} / \mathrm{L} \mathrm{NaCl}$ (at the larger peak), and the polysaccharide component OCP-2 can be obtained. 


\subsection{The average molecular weight of OCP}

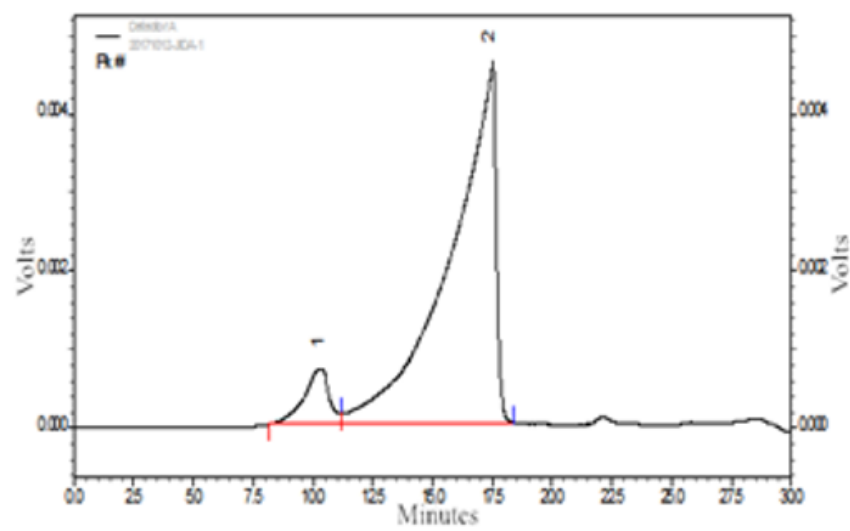

Fig. 5. HPLC profiles of purified polysaccharides

The standard curve equation is presented as follows by the GPC method: $y=-0.33601052 x+9.61945385$ $\left(R^{2}=0.9997\right)$. The high performance liquid chromatogram (HPLC) of the purified sample is as shown in Figure 5, in which peak 2 has a far larger area than peak 1. OCP-2 is a type of heteropolysaccharides, of whose major components the average molecular weight stands at $5435 \mathrm{Da}$.

\subsection{Monosaccharide composition analysis}

Figure 6 displays the GC-MS chromatogram of OCP, in which at peak 1, 2, and 3 is arabinose, 4 is mannose, 5 is galactose, and 8 is talose, while the components at peak 6,7 , and 9 are unknown. The retention time of peak 1-9 is $13.853,13.907,14.276,14.818,16.193,16.618$, $16.949,17.072,17.790 \mathrm{~min}$ respectively. It follows that OCP is composed of arabinose, mannose, galactose, talose and some other components that remain unknown, requiring further analysis based on subsequent experiments.

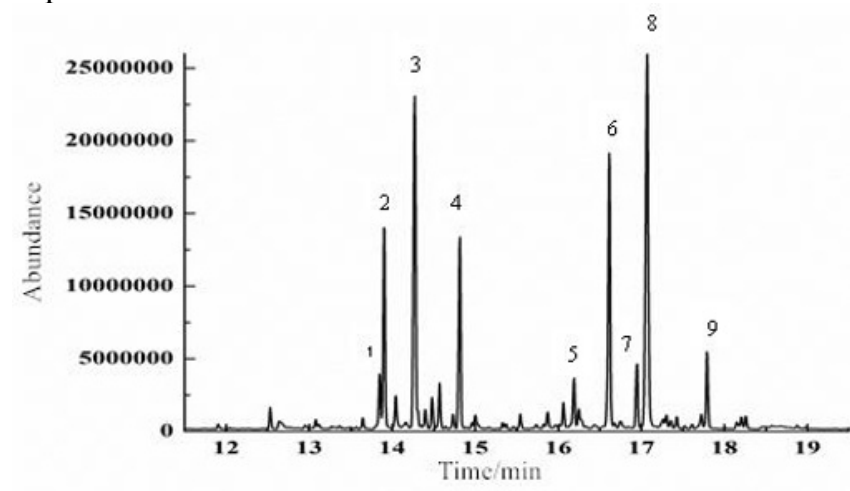

Fig. 6. GC-MS chromatogram of OCP

\section{Conclusions}

(1) The regression model of ultrasound-assisted extraction of OCP established by response surface design on the basis of single factor experiment is viable for the accurate prediction of OCP yield in the concentration range of the experiment. The optimum extraction parameters are: the ultrasonic power at $400 \mathrm{~W}$, solvent-to-sample ratio of $23: 1(\mathrm{~mL} / \mathrm{g})$, ultrasonication temperature at $53{ }^{\circ} \mathrm{C}$, and time for $36 \mathrm{~min}$, under which the yield of OCP stands at $3.54 \%$.

(2) Polysaccharides from Oenothera biennis L. leaves possess strong scavenging activity of DPPH and hydroxyl free radicals, and strong reducing power. Meanwhile certain relationship exists invariably between the dose and effect in the concentration range of the experiment.

(3) Fourier IR spectroscopy reveals that characteristic absorption peak of polysaccharides can be seen from OCP; OCP-2, a water-soluble component of polysaccharides obtained by the the DE-52 cellulose column chromatography, is identified by HPLC as heteropolysaccharides, whose major components, including arabinose, mannose, galactose, and talose, have an average molecular weight of $5435 \mathrm{Da}$

\section{Acknowledgments}

This work was funded by the science and technology planning project of Jilin Province (SF2017-6-4).

\section{References}

1. Zhang M. (2006) the special functions and the study progress of evening primrose, 27(4):139-141.

2. Ramona F., Valentina B., Ersilia A., et al. (2020) Phytochemical and Biological Screening of Oenothera Biennis L Hydroalcoholic Extract. J. Biomolecules, 10(6): 818

3. Kakarab M.U., Naveed M., Saeed M., et al. (2020) A review on structure, extraction, and biological activities of polysaccharides isolated from Cyclocarya paliurus (Batalin) Iljinskaja. J. International Journal of Biological Macromolecules, 156: 420-429.

4. Zeng G., Ju Y., Shen H., et al. (2013) Immunopontentiating activities of the purified polysaccharide from evening primrose in $\mathrm{H} 22$ tumor-bearing mice. J. International Journal of Biological Macromolecules, 52(1): 280-285.

5. Dubois M., Gilles K.A., Hamilton J.K., et al. (1956) Colorimetric Method for Determination of Sugars and Related Substances. J. Analytical Chemistry, 28(3): 350-356.

6. Chang F., Wang S.Y., Chen F., (2015) Extraction and Deproteinization of Polysaccharides from Guizhou wild Paederia scandens[J]. Development of Fine Chemicals, 2:294-300.

7. Poppe, C., Mcfadd.en K.A., Brouwer A.M., et al. (2012) Characterization and antioxidant activities of polysaccharides from Panax japonicus, C.A. Meyer. J. Carbohydrate Polymers, 88(4): 14021406.

8. Lai F. R., Wen Q. B., Lin L., et al. (2010) Antioxidant activities of water-soluble polysaccharide extracted from mung bean (Vigna radiata L.) hull with ultrasonic assisted treatment. J. Carbohydrate Polymers, 81(2): 323-329. 
9. Yang X. Q., Zhang Y. N., Wang L. L., et al. (2016) Optimization of Ultrasonic-Assisted Extraction of Pectin from Muskmelon Rind and Its Physical Characteristics[J]. Food Science 37(16):48-53.

10. Li X. L., Zhou A.G., Han Y. , (2006) Antioxidation and anti-microorganism activities of purification polysaccharide from Lygodium japonicum, in vitro. J. Carbohydrate Polymers, 66(1): 34-42.

11. Bondet V., Brand-Williams W., Berset C. (1997) Kinetics and Mechanisms of Antioxidant Activity using the DPPH. Free Radical Method. J. LWT Food Science and Technology, 30(6): 609-615.

12. Li X., Wang L.,(2015) Effect of extraction method on structure and antioxidant activity of Hohenbuehelia serotina polysaccharides. J. International Journal of Biological Macromolecules, 83: 270 .

13. Amarowicz R., Pegg R.B., Rahimi-Moghaddam P., et al. (2004) Free-radical scavenging capacity and antioxidant activity of selected plant species from the Canadian prairies. J. Food Chemistry, 84(4): 551-562.

14. Zheng Y., Li Y., Wang W. D., (2014) Optimization of ultrasonic-assisted extraction and in vitro antioxidant activities of polysaccharides from Trametes orientalis. J. Carbohydrate Polymers, 111: 315.

15. Zhu X. X., Zhang Y., Luo X. G., (2010) Studies on Structure Characterization of Gastrodia Elata BL Polysaccharides. Food Research and Devolpment, 31(09):52-56.

16. Nie Y., Li S. Y., Ding Y., et al. (2016) Structural Characteristic of Polysaccharides from Hypsizigus marmoreus Fruit's Body and Its Antioxidant Activities. 16(11):55-61. 